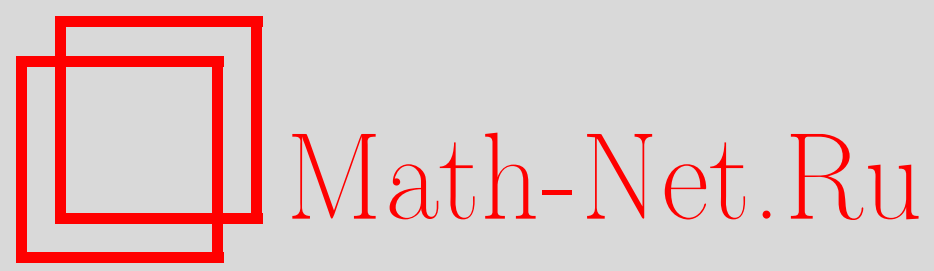

А. А. Викарчук, А. П. Воленко, М. Н. Тюрьков, О. А. Довженко, Многообразие форм роста пентагональных кристаллов при электрокристаллизации меди, Вестн. Сам. гос. техн. ун-та. Сер. Физ.-мат. науки, 2004, выпуск 27, 111-114

DOI: https://doi.org/10.14498/vsgtu285

Использование Общероссийского математического портала Math-Net.Ru подразумевает, что вы прочитали и согласны с пользовательским соглашением

http://www.mathnet.ru/rus/agreement

Параметры загрузки:

IP : 54.197 .130 .99

26 апреля 2023 г., 14:34:58 


\title{
МНОГООБРАЗИЕ ФОРМ РОСТА ПЕНТАГОНАЛЬНЫХ КРИСТАЛЛОВ ПРИ ЭЛЕКТРОКРИСТАЛЛИЗАЦИИ МЕДИ
}

\begin{abstract}
Показано, что методом электроосаждения можно получить, по крайней мере, восемь видов кристаллов меди, имеющих одну или шесть осей пентагональной симметрии. Рассмотрень особенности их строения и возможные механизмы образования и роста. Предполагается, что различные пентагональные кристалль, сформировавшиеся при электрокристаллизации, имеют одну дисклинационную природу.
\end{abstract}

Частицы с пентагональной симметрией, запрещенной законами классической кристаллографии, интенсивно изучаются на протяжении последних десятилетий. В настоящее время пятерная симметрия обнаружена практически у всех ГЦК-металлов при различных видах кристаллизации. Однако наибольших размеров такие кристаллы достигали лишь при электролитическом способе их получения [1]. Среди разнообразных моделей образования и роста пентагональных кристаллов наиболее приемлемой и объясняющей известные экспериментальные факты является дисклинационная модель [2,3]. В то же время энергетически выгодным образование дисклинаций, как показано в [2,4], может быть только в случае частиц размером не более сотен нм; поэтому наличие дисклинаций в более крупных пентагональных кристаллах (иногда до сотен мкм [1]), полученных электрохимическим осаждением, является дискуссионным. Исследование происхождения и особенностей внутреннего строения сравнительно крупных пентагональных кристаллов представляет большой интерес для теории кристаллизации, так как позволит решить ряд вопросов теории прочности и пластичности, в частности, изучить влияние одиночных дисклинаций на свойства твердых тел, проверить теоретические модели релаксации неоднородной упругой энергии, связанной с дисклинацией, разобраться с механизмами образования и роста таких кристаллов. С точки зрения практического применения, необычные свойства дефектных структур пентагональных кристаллов могут быть определяющими для создания материалов со специфическими свойствами, в частности, порошков и композитов из пентагональных кристаллов, бакиболов, пентагональных «усов». Последние экспериментальные результаты говорят о возможности получения пленок и фольг, состоящих из пентагональных кристаллов, которые, по нашему мнению, должны обладать особыми электрическими и физико - механическими свойствами.

Варьируя условия электроосаждения и тип подложки, нам удалось получить по крайней мере восемь видов пентагональных кристаллов, различающихся между собой внешней формой, размерами и внутренним строением. Они могут образовываться из двумерных и трехмерных зародышей и содержат двойниковые субграницы, сходящиеся на оси симметрии пятого порядка и разбивающие кристалл по плоскости $\{111\}$ на сектора с ГЦК-решеткой.

Пентагональные кристаллы из двумерных зародышей образуются в глубине покрытия и имеют конусообразную форму, вытянутую вдоль направления $<110>$. Модель образования таких кристаллов детально описана в работе [5], суть которой сводится к следующему: на подложке с текстурой $<110>$ возможно образование из двумерных зародышей микрокристалла, содержащего оборванную и наклоненную к подложке двойниковую границу типа $<110>(111)$, имеющую ростовое происхождение, эквивалентную по своему упругому полю напряжений частичной дисклинации мощностью $\omega=70,5^{\circ}$. В процессе роста кристалла создаются энергетические и кинетические предпосылки для двойникования по двум плоскостям $\{111\}$, перпендикулярным к плоскости (110), при этом часть упругой энергии релаксирует. Двойникование приводит к переориентации недеформированной части кристалла, что создает условие для дальнейшего двойникования еще по двум плоскостям $\{111\}$. При этом кристалл разбивается на пять секторов, разделенных между собой двойниковыми границами, сходящимися на 7градусной частичной дисклинации. Одна из границ имеет ростовое происхождение, она наклонена к плоскости подложки, а четыре другие границы раздела образуются деформационным путем в процессе последующего роста кристалла. Они перпендикулярны к подложке. Реализуется энергетически оправданная [6] схема преобразования 70-градусной частичной дисклинации в 7-градусную с обрывающимися на ней пятью двойниковыми границами $\left(E_{70} \rightarrow E_{7}+5 \gamma_{111}\right)$. 
Проведенные нами исследования показывают [1], что рост кристаллов при электрокристаллизации меди на индифферентных подложках всегда начинается из трехмерных зародышей кластеров, из которых на начальных этапах образуются островки роста, имеющие сферическую или полусферическую форму и некристаллическое строение.

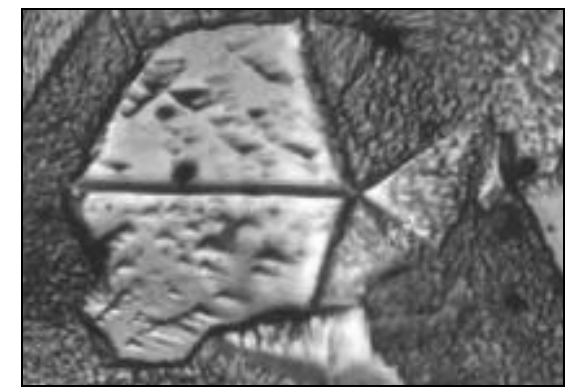

$a$

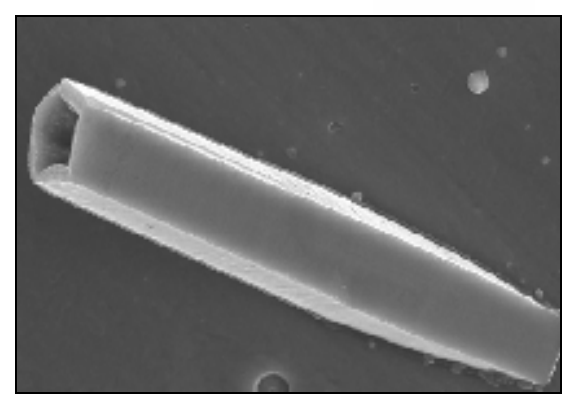

2

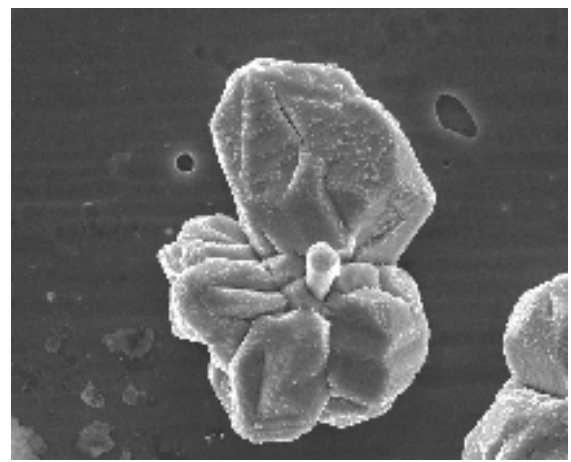

ж

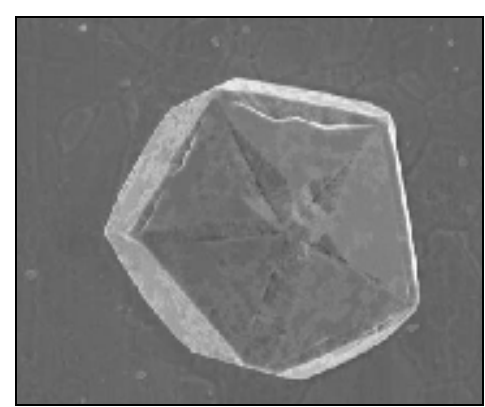

$\sigma$

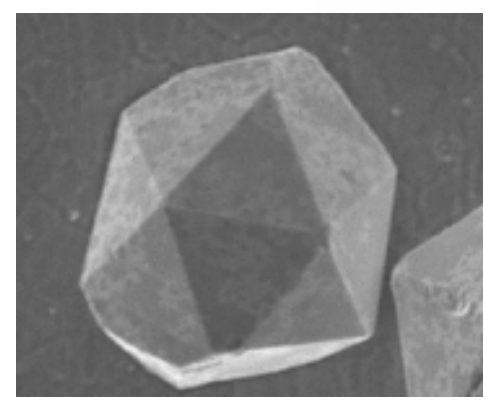

$\partial$

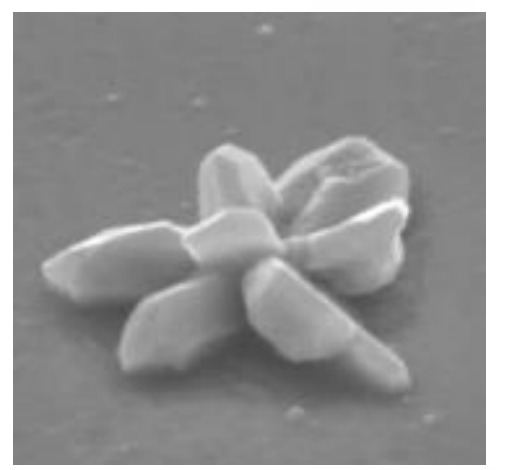

2.5 M1KM

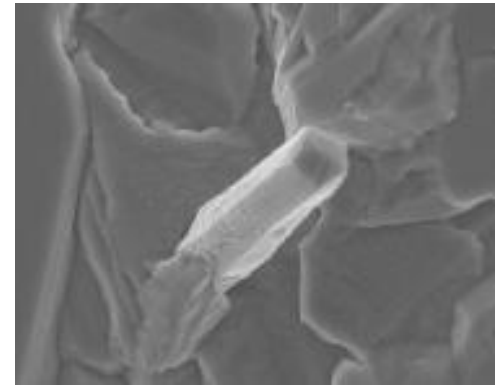

$2.5 \mathrm{MKM}$

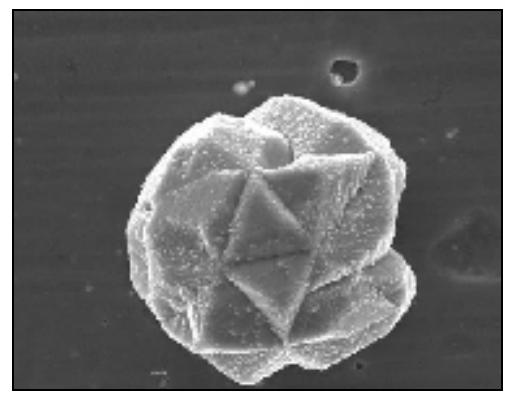

5 MKM1

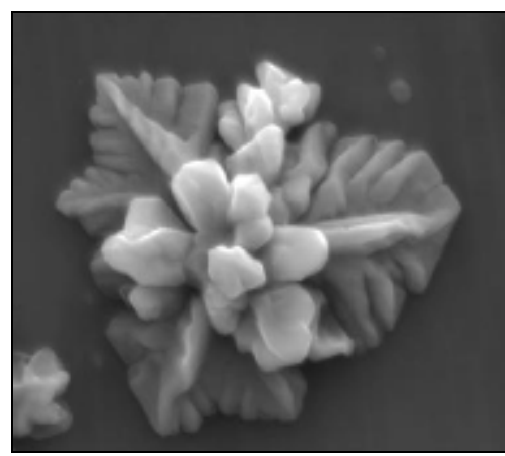

5 нкм

Р и с. 1. Кристаллы с пентагональной симметрией.

При достижении определенных размеров (для меди $~ 1$ мкм) сферические островки приобретают огранку, и из них образуются микрокристаллы разнообразной формы (рис.1) в зависимости от типа подложки и условий электролиза. При малых плотностях тока (низкое перенапряжение) в условиях, близких к термодинамическому равновесию, формируются пентагональные кристаллы с одной осью симметрии пятого порядка в виде пентагональных шайб, призм и трубок (рис.1, $a$-г), образованные предположительно из трехмерных декаэдрических кластеров. Пентагональные кристаллы с шестью осями симметрии пятого порядка в виде бакибол или звездчатых кристаллов (рис. $1, \partial, e$ ) образуются предположительно из икосаэдрических кластеров. Мы предполагаем, что при низких перенапряжениях на индифферентной подложке вначале образуется трёхмерный кластер, имеющий декаэдрическое или икосаэдрическое расположение атомов. Возможно, этому способствует адсорбция примеси. В настоящее время доказано [2,3], что малые декаэдрические или икосаэдрические частицы более устойчивы, чем обычные кристаллические зародыши, причём при малых размерах энергетически выгодной для них является сферическая форма. Таким образом, в нашем случае из трёхмерных декаэдрических кластеров формируются островки роста сферической формы. На следующем этапе роста в островке происходит перегруппировка атомов из некристаллической декаэдрической структуры в кристаллическую с образованием дефекта кристаллического строения в виде дисклинации 
мощностью $\pi / 3$. Этому способствуют: сравнительно малая энергия дисклинации в кристаллах размером менее 0.1 мкм, высокое внутреннее давление за счёт поверхностного натяжения и малого радиуса частицы, а также уменьшение поверхностной энергии за счёт появления у островка огранки.

При увеличении размеров кристаллов до $1-3$ мкм, упругая энергия, связанная с дефектом, релаксирует путём образования от 2 до 5 двойниковых границ. Дисклинация мощностью $\omega=\pi / 3$ преобразуется в процессе роста кристалла в пентагональный кристалл, содержащий частичную дисклинацию в $7^{\circ} 20^{\prime}$ и пять обрывающихся на ней двойниковых границ, причём ни одна из них особо не выделена.

В конечном итоге, из декаэдрических кристаллов, содержащих 7-градусную частичную дисклинацию и имеющих одну ось симметрии пятого порядка, вырастают пентагональные кристаллы, внешние грани (со стороны электролита) которых являются плотноупакованными плоскостями типа (111), сходящимися в одной вершине, причём вдоль двойниковых границ могут наблюдаться «канавки», образующие входящий угол на двойниковых границах (рис.1, б). Наличие такого угла способствует преимущественному росту всего пентагонального кристалла вдоль направления $<110>$, а направление $<112>$ является предпочтительным для роста каждого сектора в кристалле.

Ещё более вероятным является образование из сферических островков роста с некристаллической структурой устойчивых икосаэдрических кристаллов, содержащих частичную дисклинацию мощностью $0.48 \pi$ с обрывающимися на ней двойниковыми границами и имеющих шесть осей пятого порядка. Для икосаэдрических кристаллов активными центрами кристаллизации являются выходы дисклинаций, т.е. шесть осей симметрии пятого порядка, из них впоследствии образуются звездообразные пентагональные кристаллы (рис.1, д,e).

При увеличении перенапряжения на катоде уже при малых размерах растущих пентагональных кристаллов (около 1 мкм) наблюдаются отклонения от декаэдрической формы: преимущественный рост получают участки, растущие вдоль двойниковых границ и осей пятого порядка. Таким путем из микрокристалла в виде декаэдра, имеющего размер порядка 1 мкм, вырастает пятилепестковое образование размером 10-15 мкм. Каждый лепесток содержит двойниковую границу, но все они соорганизованы вокруг одного общего центра кристаллизации в виде пентагональной призмы (рис. 1, ж).
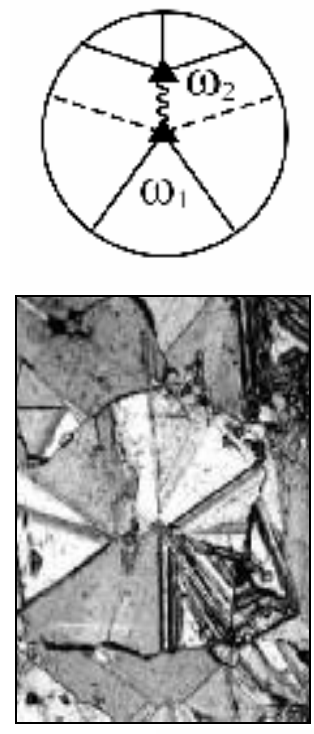

$a$
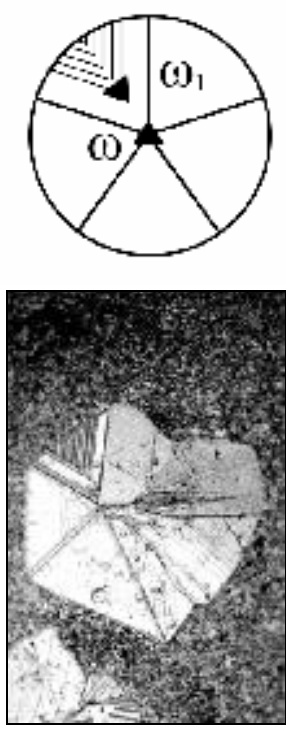

б
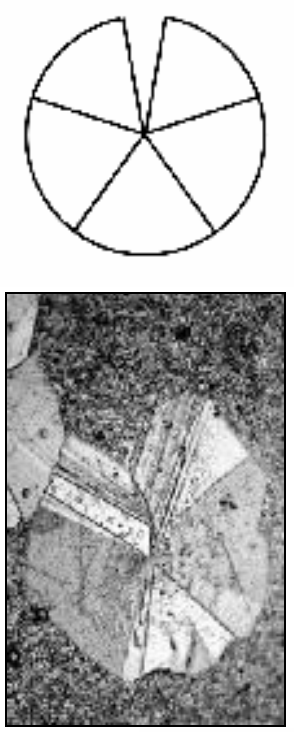

B
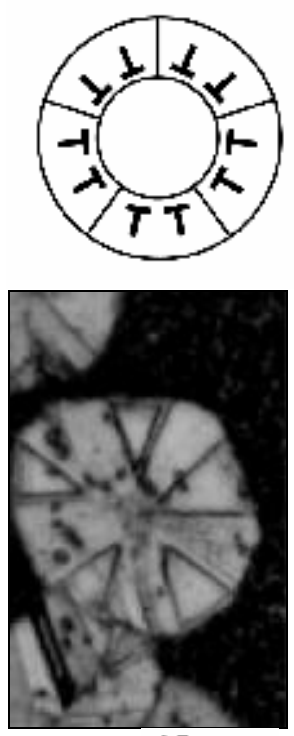

15 MKY

Р и с. 2. Наблюдаемые в эксперименте различные каналы релаксации полей упругих напряжений в пентагональных малых частицах непосредственно перед разрушением пятерной симметрии.

Кроме пятилепестковой конфигурации образуются кристаллы типа «ежи», у которых преимущественных направлений роста от 6 до 11 (рис.1, з), причём ни одно из них не было столь явно выражено. Поперечный шлиф такого кристалла-агрегата показывает наличие 7 - 10 двойниковых границ, сходящихся в одном узле. Из таких кристаллов при дальнейшем росте формируются дендриты (рис. $1, e)$. 
Мы полагаем, что пентагональная симметрия кристаллов однозначно говорит о дисклинационном механизме их формирования [1]. То, что такие кристаллы могут вырасти до размеров в сотни мкм, можно объяснить [7] релаксацией упругого поля дисклинации различными способами (рис.2).

При увеличении размеров отдельных пентагональных кристаллов появляются следующие основные каналы релаксации внутренних полей упругих напряжений: расщепление узла, где сходятся двойниковые границы, с излучением дислокаций (рис.2, а), образование объемного дефекта клиновидной формы, состоящего из тонких двойниковых прослоек (рис.2, б); образование открытого сектора вместо двойниковой границы (рис.2, в); образование новой фазы внутри микрокристалла с изначально пентагональной симметрией (рис.2, г); образование двойниковых прослоек, дефектов упаковки и дислокаций и т.д.

Обнаруженные в экспериментах пути релаксации внутренних полей упругих напряжений, особенно факт расщепления узла, где сходятся двойниковые границы, на два (рис.2, a), также указывают на дисклинационное происхождение пентагональных кристаллов. Многообразие возможных путей релаксации упругой энергии, связанной с дисклинацией, позволяет кристаллу вырасти до достаточно больших размеров, сохраняя пятерную симметрию.

\section{БИБЛИОГРАФИЧЕСКИЙ СПИСОК:}

1. А.А. Викарчук, А.П. Воленко, И.С. Ясников // Техника машиностроения. 2003. №3.С.29-33.

2. V.G. Gryaznov, I. Heidenreich, A.M. Kaprelov, S.A. Nepijko, A.E. Romanov, I. Urban. // Crystal Research Technology, 1999. V.34, № 9. P. 1091-1119.

3. В.Г. Грязнов, А.М. Капрелов, А.Е. Романов. Пентагональная симметрия и дисклинации в малых частицах// Дисклинации и ротационная деформация твердых тел. Сб. трудов. Л.: Изд-во ФТИ. 1986. С.47-83.

4. В.А. Лихачев, А.Е. Волков, В.Е. Шудегов. Континуальная теория дефектов. Л.: Изд-во ЛГУ. 1986. 232 с.

5. А.А. Викарчук, А.П. Воленко, В.В. Окулов, И.С. Ясников Дислокационно-дисклинационные структуры, формирующиеся при электрокристаллизации ГЦК-металлов // Материаловедение, 2002. № 11(68). С.47 - 53.

6. Wit. R. Partial disclinations // J. Phys. C.: Solid State Phys. 1972. V.5. P.529-534.

7. V.G. Gryaznov, A.M. Kaprelov, A.E. Romanov, L.A. Polonskii. Channels of relaxation of elastic stresses in pentagonal nanoparticles // Phys. stat. sol. (b), 1991. V.167. №2. P. 441-450.

УДК 541.138 .3

\section{А.П. Воленко}

\section{ВЛИЯНИЕ УСЛОВИЙ ЭЛЕКТРОЛИЗА НА ФОРМЫ РОСТА КРИСТАЛЛОВ НА НАЧАЛЬНОМ ЭТАПЕ ЭЛЕКТРОКРИСТАЛЛИЗАЦИИ МЕДИ}

Показано, что на начальном этапе электрокристаллизации на подложках с малой адгезией с увеличением плотности тока наблюдаются пентагональные кристалль с одной и шестью осями симметрии пятого порядка, пентагональные призмь и трубки, а также сферолить и дендритьл. Обсуждаются особенности их строения и механизмы формирования.

Электронной промышленности требуются покрытия и пленки со специфическими свойствами. Вместе с тем процессы структурообразования ГЦК-металлов при электрокристаллизации, определяющие свойства формирующихся пленок, фольг и покрытий, изучены недостаточно. Особый интерес представляют исследования, направленные на выявление условий появления кристаллов с пятерной симметрией при электрокристаллизации металлов, с которыми связывают надежды на получение пленок и фольг с принципиально новыми свойствами. В настоящей работе изучались особенности начального этапа электрокристаллизации меди на индифферентных подложках. Медь выбрана в качестве модельного материала, так как относительно хорошо изучена электрохимическая сторона процесса электроосаждения меди из разнообразных электролитов и в различных условиях (температура, плотность тока); имеется большое количество достоверных сведений о характере структурных несовершенств в меди вообще; исследованию структуры этого материала и взаимосвязи с электрохимическими и технологическими факторами посвящено наибольшее число работ зарубежных и отечественных учёных [1].

Учитывая то, что на практике в гальванопластике медные фольги получают на катодахбарабанах, изготовленных из нержавеющей стали и титана, нами в качестве катода использовались подложки из: полированной нержавеющей стали, титана и ионно-плазменного покрытия 